\title{
MENTAL HEALTH AND SUBSTANCE USE AMONG CZECH SEXUAL MINORITIES
}

Michal Pitoňák1 (michal.pitonak@nudz.cz), Pavla Chomynová ${ }^{123}$

${ }^{1}$ National Institute of Mental Health, ${ }^{2}$ Charles University,

${ }^{3}$ Czech National Monitoring Centre for Drugs and Addictions $19^{\text {th }}$ WPA World Congress of Psychiatry

Lisbon, 21-24 August, 2019

$3,8 \%$ Sex minorities $(1,1 \% \mathrm{~L} / \mathrm{G}+2,7 \% \mathrm{~B})$

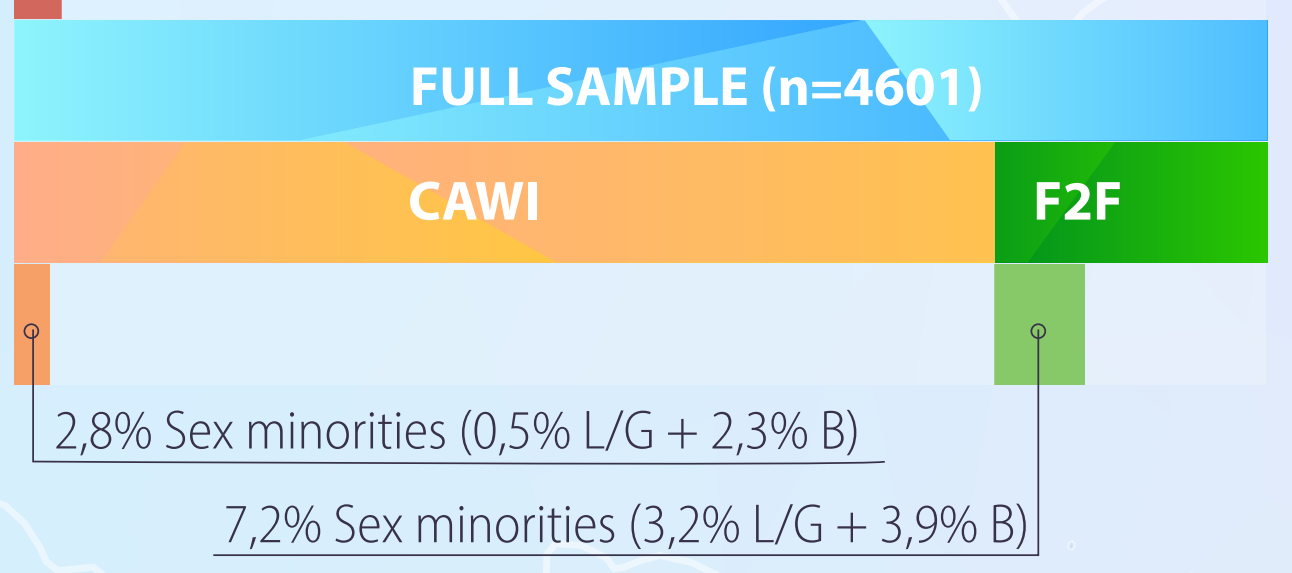

Czech national survey on substance use

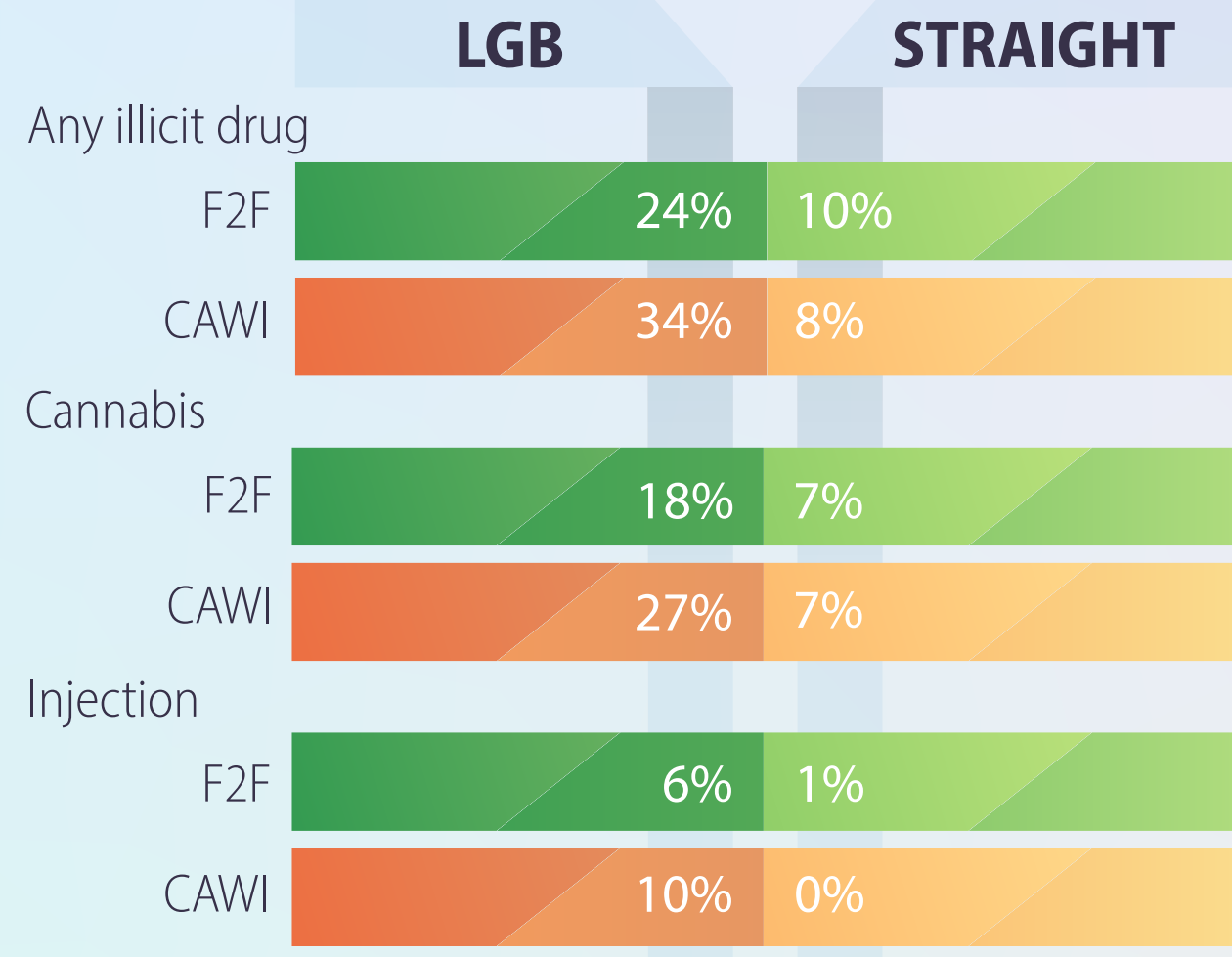

LOGISTIC REGRESSION

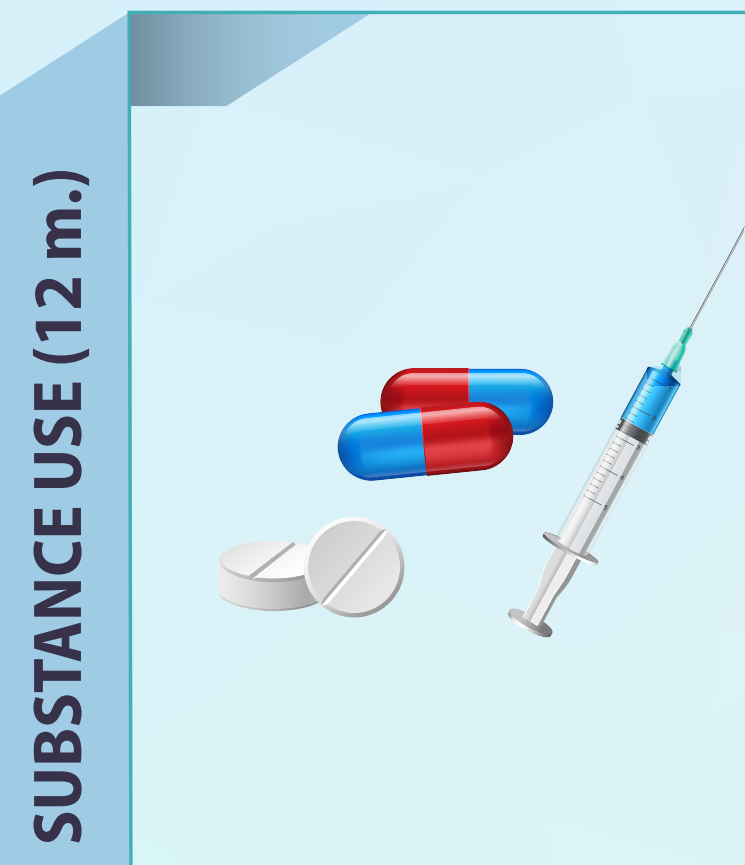

Good mental health

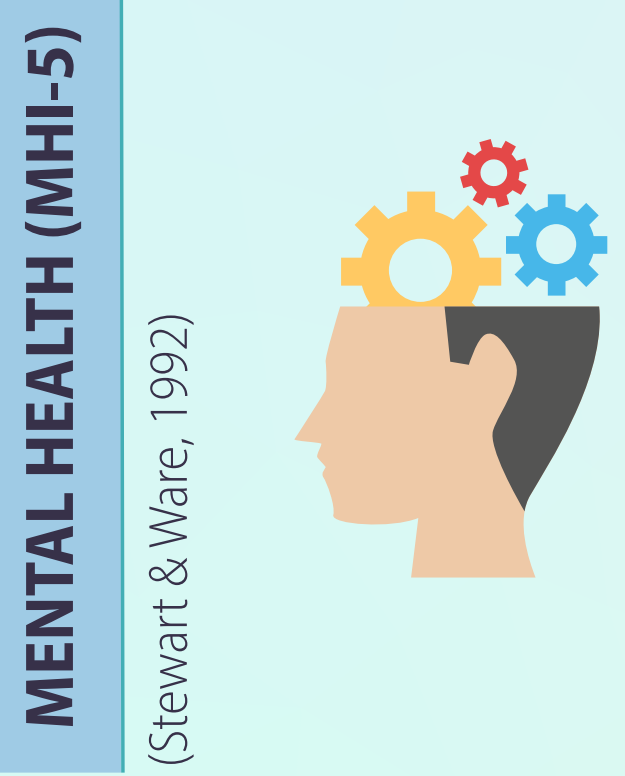

F2F

CAWI

Presence of anxiety/depression symptoms

F2F

$10 \%$

CAWI

$17 \%$

High probability of mental health disorder

$\mathrm{F} 2 \mathrm{~F}$

$9 \%$

CAWI

$8 \% \quad 9 \%$

Sexual minorities identified in both samples were more likely to experiment with (illicit) substance use in the last 12 months.

$(\mathrm{OR}=2.57,95 \% \mathrm{Cl}: \mathbf{1 . 7 6 - 3 . 7 5 )}$

In case of injecting drug use, the OR increased to 12.80 (95\% Cl: 6.14-26.67)

High scores ( $\geq 15$ points) indicate good menta health, while 13-14 points suggest higher presence of anxiety-depression symptoms and $\leq 12$ points indicate high probability of mental health disorders. For the purposes of our analysis, the scale was dichotomized into 0 'good mental health', and 1 'higher probability of mental health disorders'. Sexual minority status predicted a higher probability of mental health disorders.

$(\mathrm{OR}=2.02,95 \% \mathrm{Cl}$ 1.37-2.98)

Satisfaction with life

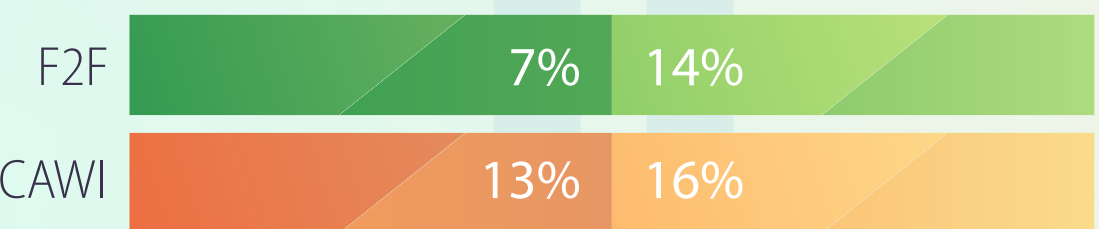

Sexual minorities were slightly less often satisfied with their lives compared to straight population. These results were not statistically significant.

$(O R=0.68,95 \%$ Cl $0.43-1.05)$

\section{Acknowledgements:}

This study is a result of the research funded by the Czech Science Foundation as the project GA ČR P407 n. 19-14801S "Minority stress in non-heterosexuals in the Czech Republic".

\section{Conclusion:}

Sexual minorities represent a vulnerable group from the perspective of substance use and psychological distress. Programs targeting the health and well-being of sexual minorities should be developed and should pay special attention to substance use and mental health issues in this group. Most importantly, we should be aware that these results are likely the effects of the complex workings of minority stress that needs to be further investigated in our country and beyond. 